Journal of Advanced Research in Fluid Mechanics and Thermal Sciences

\title{
Energy Analysis of Vapor Compression Refrigeration Cycle Using a New Generation Refrigerants with Low Global Warming Potential
}

\author{
Rabah Touaibi ${ }^{1, *}$, Hasan Koten ${ }^{2}$ \\ Faculty of Science and Technology, Laboratory of Industrial Fluids, Measurements and Applications, Khemis Miliana University, Algeria \\ Istanbul Medeniyet University, Mechanical Engineering Department, Istanbul, 34700, Turkey
}

\section{ARTICLE INFO ABSTRACT}

Article history:

Received 25 April 2021

Received in revised form 12 August 2021

Accepted 15 August 2021

Available online 20 September 2021

\section{Keywords:}

New generation; Refrigeration Cycle; Energy Analysis; ecological properties; GWP

\begin{abstract}
An energy analysis study carried out on a vapor compression refrigeration cycle using refrigerants with low global warming potential (GWP) of the Hydro-Fluoro-Olefin (HFO) type, in particular R1234yf and R1234ze fluids to replace HFC refrigerants. Computer code was developed using software for solving engineering equations to calculate performance parameters; for this, three HFC type fluids (R134a, R404A and R410A) were selected for a comparative study. The results showed that R1234ze is the best refrigerant among those selected for the mechanical vapor compression refrigeration cycle. The thermodynamic analysis showed the effect of the evaporator temperature ($22{ }^{\circ} \mathrm{C}$ to $\left.10^{\circ} \mathrm{C}\right)$ and the condenser temperature $\left(30^{\circ} \mathrm{C}\right.$ to $\left.50{ }^{\circ} \mathrm{C}\right)$ on the steam cycle performance. Compression refrigeration, including the coefficient of performance. The results showed that the HFO-R1234ze with low GWP gives the best coefficient of performance of 3.14 close to that of the R134a fluid (3.17). In addition, R1234ze is considered an alternative fluid to R134a for their ecological properties.
\end{abstract}

\section{Introduction}

The demand for cold has increased due to multiple applications such as domestic, commercial and industrial cold. According to a report by the Economist Intelligence Unit, the domestic refrigeration and residential air conditioning accounted for $62 \%$ of total cooling demand; where the refrigeration and industrial transport sectors will experience the fastest growth until 2030 [1]. The international market is constantly looking for more environmentally friendly refrigerants with even less impact on the environment. Currently, new generation fluids are attracting the most attention.

Heavy fuel oils are considered new generation fluids and attract the most attention. Most of the refrigeration systems currently in use are mechanical vapor compression systems. These systems use refrigerants as the working fluid, the majority of which are considered air pollutants. The environmental constraints set out in the Montreal Protocol (1987) on the protection of the ozone layer and the Kyoto Protocol in 1979 on the protection of the climate requires the search for new refrigerants. Halogenated hydrocarbons with high ozone depletion potential (ODP) have been

\footnotetext{
* Corresponding author.

E-mail address: ra.touaibi@gmail.com
}

https://doi.org/10.37934/arfmts.87.2.106117 
banned under the Montreal Protocol due to their harmful effects on the ozone layer which protects the planet from ultraviolet rays [2-6].

The environmental impact is expressed in terms of the ozone depletion potential (ODP) and the global warming potential (GWP). These parameters become a more efficient factor in the selection of refrigerants. Due to the Montreal Protocol of 1987, some refrigerants have been eliminated, such as R11, R12, R113, etc. due to their high ODP (1 or slightly less). In addition, European regulations will stop using high GWP refrigerants (such as R134a) in the near future. Hydrofluoroolefin (HFO) is then the promising alternative which gives an almost zero GWP. HFO is an unsaturated HFC and it is the fourth generation of fluorinated gases [7-9]. Nowadays, the attention of all researchers is focused on the feasibility of replacing HFC R134a with HFOs [10-13]. Many works are currently in search of new ecological fluids which can have less impact on the ozone layer thus also on the global warming of our planet. The effects of saturation temperature, mass flow of refrigerant and superheating of steam have been studied by Longo et al., [14]; they observed that R152a has much higher heat transfer coefficients than all other studied refrigerants R134a, R290 and R1234ze.

Antunes et al., [15] presented an experimental study of a refrigeration system to replace HCFC22 with other halogenated refrigerants such as HFC-438A, HFC-404A, HFC-410A and HFC-32, as well as hydrocarbons HC-290 and HC-1270. The results showed that natural refrigerants had the best coefficient of performance. Mota-Babiloni et al., [16] have proposed R32 to replace R410A, especially in residential air conditioning systems; they also showed that R32 has good heat transfer characteristics compared to R410A and other lower GWP alternatives. Fang et al., [17] presented a work which presents a thermodynamic analysis of a single-phase supersonic ejector working with the R134a as well as the refrigerants R1234yf and R1234ze. Comparisons were made regarding the performance of the ejector under various operating conditions and the proportions of the refrigerant mixture. R1234yf seems to be a good candidate for the immediate replacement of R134a. BelmanFlores et al., [18] modeled a refrigeration system to compare three refrigerants: R134a, R450A and R513A. The results show that R450A has a slightly lower cooling capacity than R134a, which represents a $10 \%$ reduction in cooling capacity.

Yataganbaba et al., [19] presented a study based on the energetic analysis of a two-evaporator vapor compression refrigeration system using R1234yf, R1234ze and R134a as refrigerants. The effects of evaporator and condenser temperatures on exergy destruction and system efficiency have been studied. R1234yf and R1234ze, which constitute good alternatives to R134a as regards their ecological properties, constitute the main finding of this study. Mendoza Miranda et al., [20] presented a variable speed liquid chiller model incorporating a compressor model based on Buckingham's theorem to predict system performance when R134a is replaced by R1234yf. Model results indicate that $\mathrm{R} 1234 \mathrm{yf}$ has a reduction in the coefficient of performance (COP) compared to R134a.

Mota-Babiloni et al., [21] carried out a study on high temperature heat pumps based on vapor compression used for the recovery of industrial waste heat at low temperatures, which can help to mitigate climate change; they also presented a high-temperature cascade-based heat pump that uses refrigerants with low global warming potential (GWP). Angelo et al., [22] presents an evaluation of the performance of a vapor injection refrigeration system using an R290 / R600a refrigerant mixture. They found that the COP of the vapor injection refrigeration cycle is 16 to $32 \%$ higher than that of a vapor compression cycle. Makhnatch et al., [23] seek to explore alternatives to refrigerants with low global warming potential in a three-stage cascade refrigeration system; results show that R1150 can replace R14 in low temperature cycles. R41 and R170 can replace R23 in the medium temperature cycle and the refrigerants of R717, R152a and R161 are recommended in the high temperature cycle. Rashed et al., [24] have dimensioned a single-phase supersonic steam ejector to study the effect of 
operating conditions on system performance parameters, such as the COP report. They have shown that the R1234yf fluid will be a potential alternative to the hydrofluorocarbon (HFC) -based R134a currently used. Mateu-Royo et al., [25] studied the feasibility of three refrigerants R1224yd, R1233zd and R1336mzz with low global warming potential (GWP), as alternatives to R245fa in the high temperature heat pump for the recovery of low-quality heat. They have shown that R1233zd improves COP by around $27 \%$ compared to R245fa.

Following bibliographic research, current research is migrating to natural refrigerants and to refrigerants with low global warming potential (GWP) in order to reduce the impact of man on climate change. The objective of this work is to make an energy analysis of a vapor compression refrigeration cycle using two new generation low GWP fluids (R1234yf and R1234ze) by comparing its performance when it works with fluids that are characterized by a high GWP.

\section{Methodology}

\subsection{Description of System}

The vapor compression refrigeration system is the most widely used refrigeration system today for air conditioning in large public buildings, private homes, hotels, hospitals, theaters, and restaurants. The system has four essential components: A compressor which is a mechanical device that increases the pressure of a gas by causing the volume of sound (similar to a pump). A condenser unit used to condensate a substance from its gaseous state to its liquid state, generally by cooling, an expansion valve and Evaporator (Figure 1).

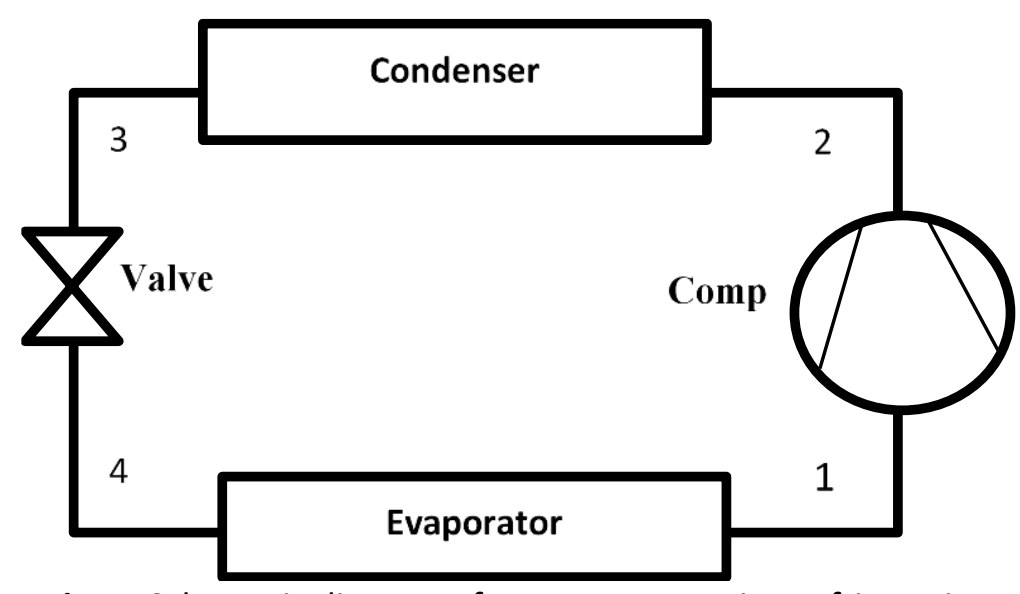

Fig. 1. Schematic diagram of vapor compression refrigeration

\subsection{Thermodynamic Analysis}

In this section, a thermodynamic modelling study is presented and the mass balance is defined as follows [26-28]

$\sum \dot{m}_{\text {in }}=\sum \dot{m}_{\text {out }} s$

where, $\dot{m}$ is the mass flow rate $(\mathrm{kg} / \mathrm{s})$, According to first law of thermodynamics, the energy balance equation is

$\sum \dot{m}_{\text {in }} h_{\text {in }}+\sum \dot{Q}_{\text {in }}+\sum \dot{W}_{\text {in }}=\sum \dot{m}_{\text {out }} h_{\text {out }}+\sum \dot{Q}_{\text {out }}+\sum \dot{W}_{\text {out }}$ 
where; $\dot{Q}, \dot{W}$, and $h$ are the heat transfer rate, work rate and specific enthalpy.

The energy analysis of the Vapor Compression Refrigeration Cycle requires the application of the first law of thermodynamics. The general equations corresponding to this principle are presented below (Table 1).

Table 1

Energy balance of vapor compression refrigeration cycle

\begin{tabular}{ll}
\hline Components & Energy balance equations \\
\hline Compressor & $\dot{m}_{1} h_{1}+\dot{W}_{\text {Comp }}=\dot{m}_{2} h_{2}$ \\
Condenser & $\dot{m}_{2} h_{2}=\dot{m}_{3} h_{3}+\dot{Q}_{\text {Cond }}$ \\
Expansion valve & $\dot{m}_{3} h_{3}=\dot{m}_{4} h_{4}$ \\
Evaporator & $\dot{m}_{4} h_{4}+\dot{Q}_{\text {Evap }}=\dot{m}_{1} h_{1}$ \\
\hline Mass balance, $\dot{\mathrm{m}}_{1}=\dot{\mathrm{m}}_{2}=\dot{\mathrm{m}}_{3}=\dot{\mathrm{m}}_{4}=\dot{m}$ & \\
\hline
\end{tabular}

\subsection{Performance Evaluation}

The coefficient of performance of the Vapor Compression Refrigeration Cycle is determined by the following equation

$C O P=\frac{\dot{Q}_{E v a p}}{\dot{W}_{C}}$

\section{Results and Discussion}

The performance of the vapor refrigeration cycle using different refrigerants have been studied in order to see the performance of some new generation low GWP refrigerant (R1234yf, R1234ze) compared to other HFC type fluids (R134a, R404A and R407C), the thermodynamic properties of these refrigerants are listed in Table 2. These models are used in a computer program using Engineering Equation Solving (EES) software to perform the calculations and a parameter sensitivity analysis is also presented [29].

Table 2

Thermodynamic properties of the refrigerants

\begin{tabular}{llll}
\hline Refrigerants & Type & GWP & ODP \\
\hline R134a & HFC & 1430 & 0 \\
R404A & HFC & 2088 & 0 \\
R407C & HFC & 1774 & 0 \\
R1234yf & HFO & 4 & 0 \\
R1234ze & HFO & 7 & 0 \\
\hline
\end{tabular}

The study was made on a vapor compression refrigeration cycle with cooling capacity $\dot{\mathrm{Q}}_{\text {Evap }}=$ $10 \mathrm{~kW}$ and under the following conditions: $\mathrm{T}_{\text {Cond }}=30^{\circ} \mathrm{C}$ and $\mathrm{T}_{\text {Evap }}=-20^{\circ} \mathrm{C}$. It was found from the calculation results found (Table 3 ) that the new generation refrigerants with low GWP, in particular R1234yf and R1234ze, give good coefficients of performance compared to those of the HFC type. Subsequently, a parametric study was carried out in order to see the effect of certain parameters on the performance of the steam refrigeration cycle using the various refrigerants in order to see the effect of the use of new generation refrigerants, which have a low GWP compared to other HFC refrigerants. The flowchart of the computational procedure is displayed in Figure 2. 
Table 3

Performance of the vapor refrigeration cycle for different refrigerants

\begin{tabular}{lllll}
\hline Fluid & $\dot{m}[\mathrm{~kg} / \mathrm{s}]$ & $\dot{Q}_{\text {Cond }}[\mathrm{kW}]$ & $\dot{\mathrm{W}}_{\mathrm{C}}[\mathrm{kW}]$ & COP [-] \\
\hline R134a & 0.06905 & 13.15 & 3.15 & 3.174 \\
R404A & 0.08983 & 13.50 & 3.50 & 2.857 \\
R407C & 0.06465 & 13.68 & 3.678 & 2.719 \\
R1234yf & 0.09038 & 13.30 & 3.304 & 3.026 \\
R1234z & 0.07765 & 13.18 & 3.181 & 3.143 \\
\hline
\end{tabular}

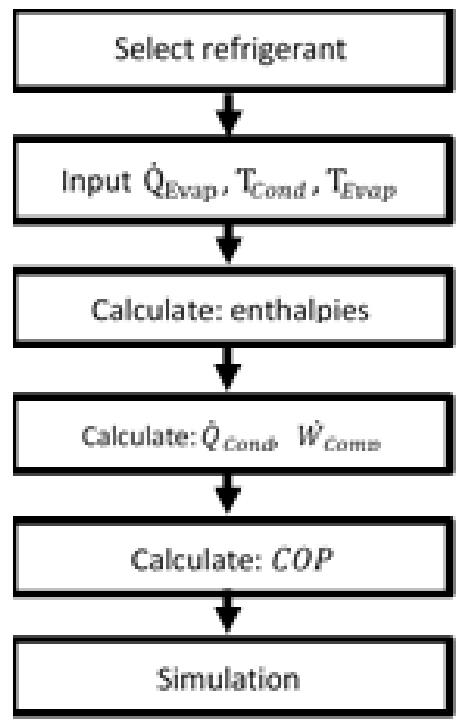

Fig. 2. Computational procedure flowchart

\subsection{Effect of the Evaporation Temperature}

The effect of the evaporation temperature on the different quantities of the refrigeration cycle has been studied in this section, in particular the coefficient of performance, mass flow of the refrigerant, mechanical power of the compressor and the thermal power of the condenser using the various HFO and HFCs refrigerants.

Figure 3 shows the effect of the evaporation temperature on the coefficient of performance using three HFC fluids (R134a, R404A and R407C) and two new generation HFO fluids (R1234yf and R1234ze). The results show that the coefficient of performance of the vapor compression refrigeration cycle increases with the increase in the evaporation temperature of each fluid used, of the HFC or HFO type. An important discovery on the results showed that HFO (R1234yf and R1234ze) gives good performance coefficients like R134a compared to other HFC fluids (R404A and R407C). The results also show that the two HFO fluids give a good coefficient of performance for positive refrigeration (air conditioning). The two fluids R1234yf and R1234ze give a coefficient of performance which approximates the coefficient of performance of the fluid R134a (3.17); R1234ze fluid gives a performance coefficient of 3.14; the advantage of the latter is that this fluid has a low GWP value (7) compared to the R134a fluid (1430). The results also show that the coefficient of performance increases with increasing evaporation temperature over the interval $\left[-20^{\circ} \mathrm{C} ; 10^{\circ} \mathrm{C}\right]$ for all fluids studied. The coefficient of performance of the R1234ze fluid of low GWP over the temperature range $\left[-20^{\circ} \mathrm{C} ; 10^{\circ} \mathrm{C}\right]$ increases from 3.14 to 10.2 . 


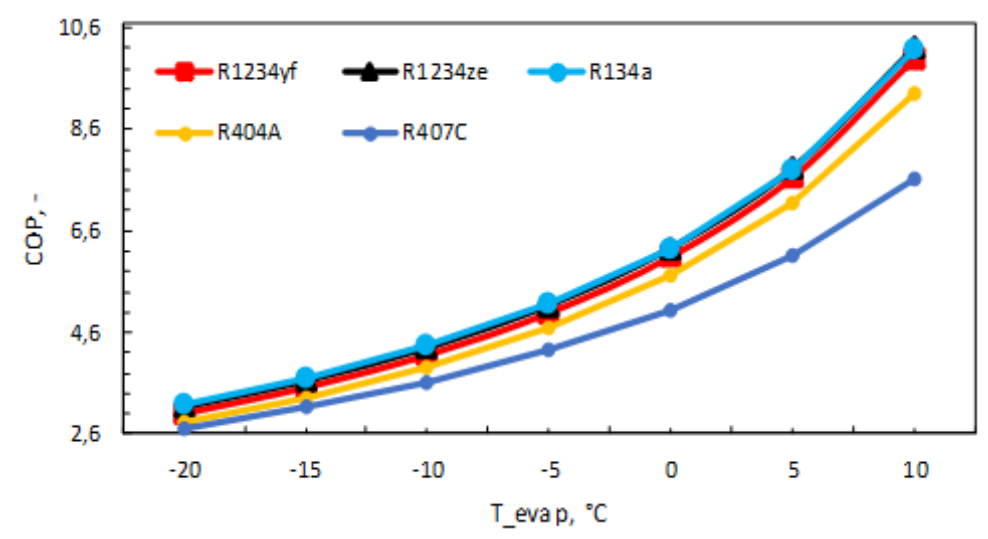

Fig. 3. Variation of the coefficient of performance as a function of the evaporation temperature

Figure 4 shows the effect of the evaporation temperature on the mass flow rate using three HFC fluids (R134a, R404A and R407C) and two new generation HFO fluids (R1234yf and R1234ze). The results show that the mass flow rate decreases with the increase in the evaporation temperature of each fluid used, of the HFC or HFO type. It should also be noted that the R1234ze fluid uses a lower mass flow rate compared to the R1234yf and R134a fluids. The mass flow rate required to supply the vapor compression refrigeration cycle decreases from $0.077 \mathrm{~kg} / \mathrm{s}$ to $0.66 \mathrm{~kg} / \mathrm{s}$ over the interval of the evaporation temperature $\left[-20^{\circ} \mathrm{C} ; 10^{\circ} \mathrm{C}\right]$.

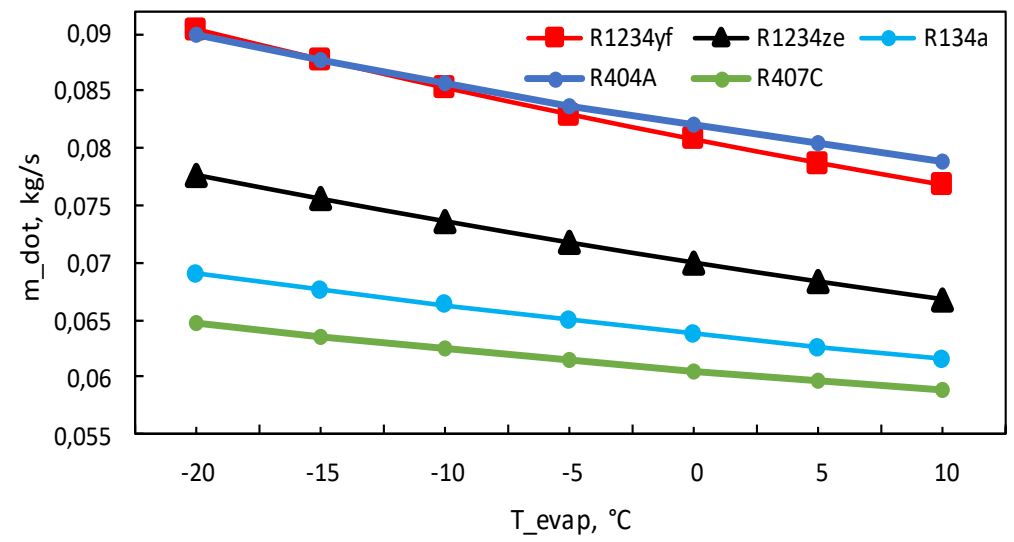

Fig. 4. Variation in mass flow as a function of evaporation temperature

Figure 5 shows the effect of the evaporation temperature on the mechanical power consumed by the compressor of the vapor compression refrigeration cycle using three HFC fluids (R134a, R404A and R407C) and two fluids of the new generation of types HFO (R1234yf and R1234ze). The results show that the mechanical power consumed by the mechanical compressor decreases with the increase in the evaporation temperature of each fluid used, of the HFC or HFO type. It should also be noted that, when working with the R1234ze fluid, the refrigeration cycle does not consume much energy at the mechanical compressor compared to other fluids of the HFC type and also compared to the R1234fy. The results also show that the vapor compression refrigeration cycle consumes less energy for positive temperatures, which shows that the system consumes less for positive 
refrigeration. For R1234ze fluid the mechanical power of the compressor decreases from $3.18 \mathrm{~kW}$ to $0.98 \mathrm{~kW}$ over the evaporative temperature range $\left[-20^{\circ} \mathrm{C} ; 10^{\circ} \mathrm{C}\right]$.

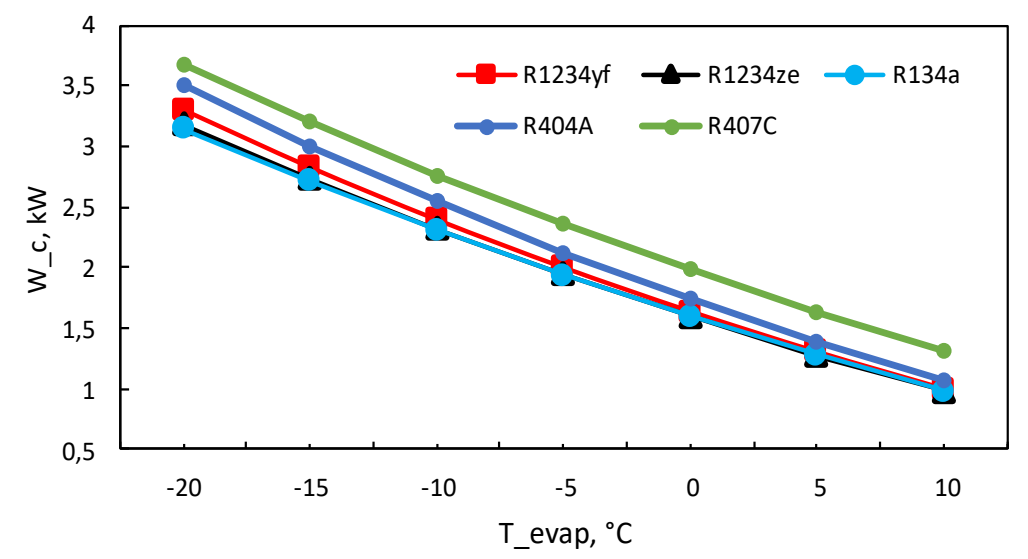

Fig. 5. Variation of the mechanical power of the compressor as a function of the evaporation temperature

Figure 6 shows the effect of the evaporation temperature on the thermal power transferred to the condenser level of the vapor compression refrigeration cycle using three HFC fluids (R134a, R404A and R407C) and two new generation HFO fluids (R1234yf and R1234ze). The results show that the thermal power transferred by the condenser decreases with the increase in the evaporation temperature of each fluid used, of the HFC or HFO type. It should also be noted that, when working with R1234ze fluid, the refrigeration cycle gives thermal energy to the condenser compared to other HFC type fluids and also compared to R1234fy fluid. For the R1234ze fluid, the results show that the power at the level of the condenser transferred to the external medium decreases from 13.18 to 10.98 over the temperature range $\left[-20^{\circ} \mathrm{C}, 10^{\circ} \mathrm{C}\right]$.

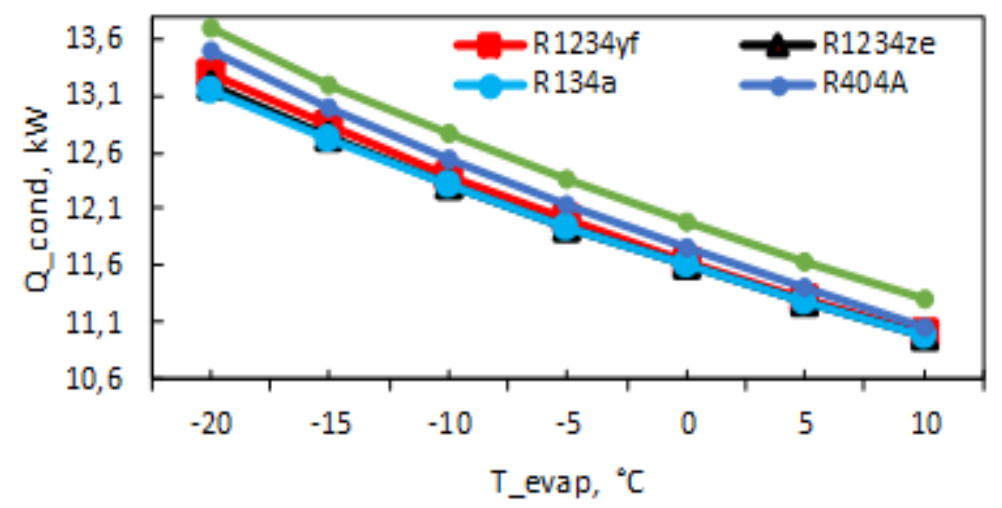

Fig. 6. Variation of the condenser power as a function of the evaporation temperature

\subsection{Effect of Condensation Temperature}

Figure 7 shows the effect of the condensation temperature on the coefficient of performance using three HFC fluids (R134a, R404A and R407C) and two new generation HFO fluids (R1234yf and R1234ze). The results show that the coefficient of performance of the vapor compression refrigeration cycle decreases with the increase in the condensation temperature of each fluid used, 
of the HFC or HFO type. An important discovery on the results showed that HFO (R1234yf and R1234ze) gives good performance coefficients like R134a compared to other HFC fluids (R404A and R407C). The results also show that the two HFO fluids give a good coefficient of performance. The R1234ze fluid gives a good coefficient of performance compared to the R1234ze fluid. For R1234ze, the results show that the coefficient of performance decreases from 3.14 to 1.86 over the condensing temperature range $\left[30^{\circ} \mathrm{C} ; 50^{\circ} \mathrm{C}\right]$.

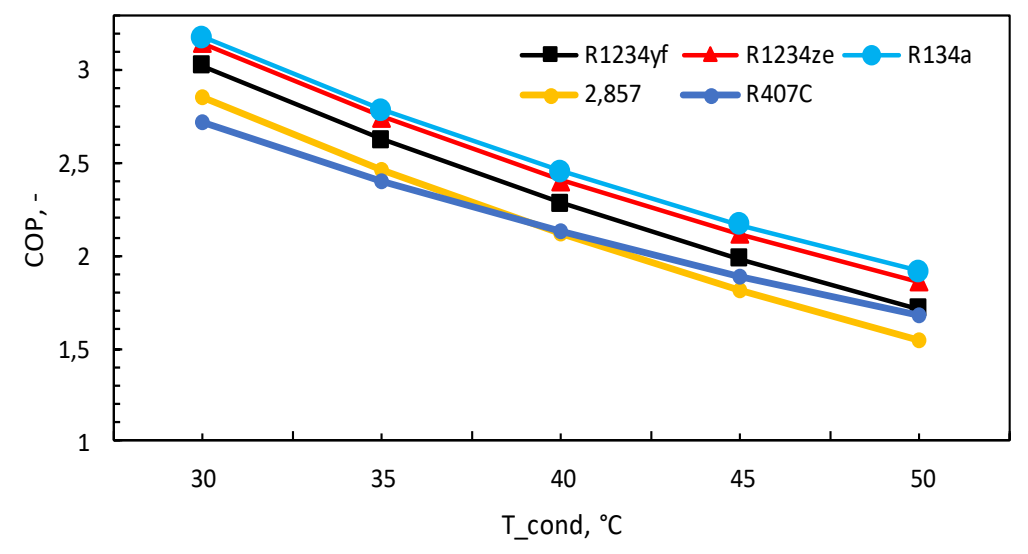

Fig. 7. Variation of the coefficient of performance as a function of the condensing temperature

Figure 8 shows the effect of the condensing temperature on the mass flow using three HFC fluids (R134a, R404A and R407C) and two new generation HFO fluids (R1234yf and R1234ze). The results show that the mass flow rate increases with the increase in the condensation temperature of each fluid used, of the HFC or HFO type. It should also be noted that the R1234ze fluid uses a mass flow rate lower than that of the R1234yf and R134a fluids. For the R1234ze fluid the mass flow rate required to supply the vapor compression refrigeration cycle increases from $0.077 \mathrm{~kg} / \mathrm{s}$ up to $0.1 \mathrm{~kg} / \mathrm{s}$ over the condensing temperature range $\left[30^{\circ} \mathrm{C}, 50^{\circ} \mathrm{C}\right]$.

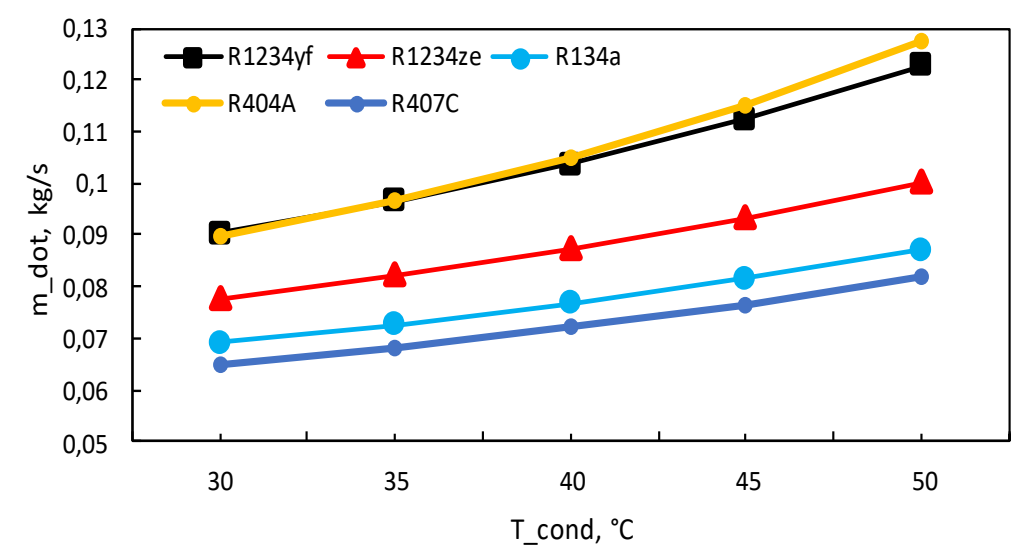

Fig. 8. Variation in mass flow as a function of condensing temperature 
Figure 9 shows the effect of the condensing temperature on the mechanical power consumed by the compressor of the vapor compression refrigeration cycle using three HFC fluids (R134a, R404A and R407C) and two new generation HFO fluids (R1234yf and R1234ze). The results show that the mechanical power consumed by the mechanical compressor increases with the increase in the condensation temperature of each fluid used, of the HFC or HFO type. It should also be noted that, when working with the R1234ze fluid, the refrigeration cycle does not consume much energy at the mechanical compressor compared to other fluids of the HFC type and also compared to the R1234fy fluid. The results also show that the vapor compression refrigeration cycle consumes less energy for low condensing temperatures, which shows that the system consumes less for one at low condensing temperatures. For the R1234ze fluid, the results show that the mechanical power required to supply the compressor for the refrigeration cycle increases from 3.18 to 5.37 .

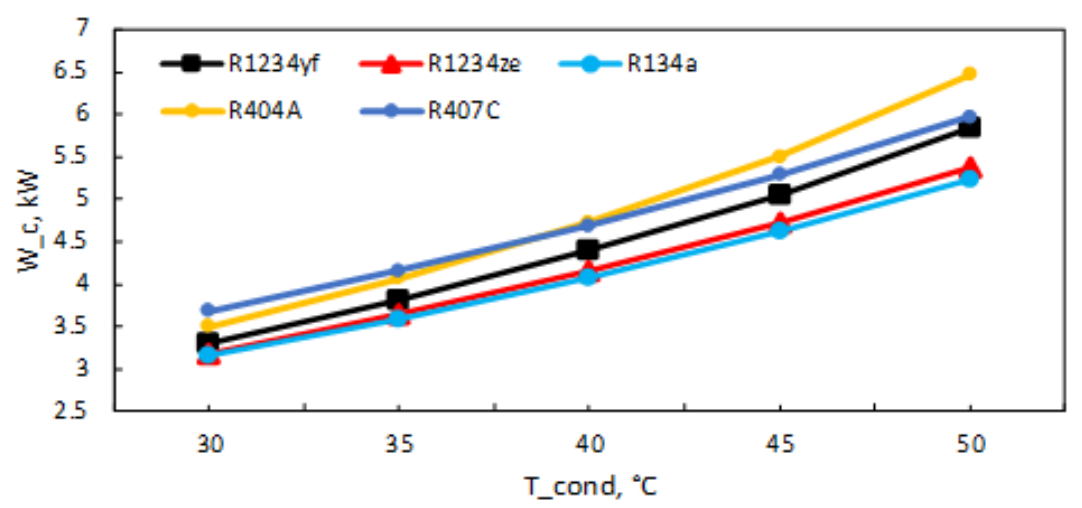

Fig. 9. Variation of the mechanical power of the compressor as a function of the condensing temperature

Figure 10 shows the effect of the condensation temperature on the thermal power transferred to the condenser of the vapor compression refrigeration cycle using three HFC fluids (R134a, R404A and R407C) and two new generation HFO fluids (R1234yf and R1234ze). The results show that the thermal power transferred by the condenser increases with the increase in the condensation temperature of each fluid used, of the HFC or HFO type. It should also be noted that, when working with R1234ze fluid, the refrigeration cycle gives thermal energy to the condenser compared to other HFC type fluids and also compared to R1234fy fluid. For the R1234ze fluid, the results show that the power at the condenser level increases from $13.18 \mathrm{~kW}$ to $15.38 \mathrm{~kW}$.

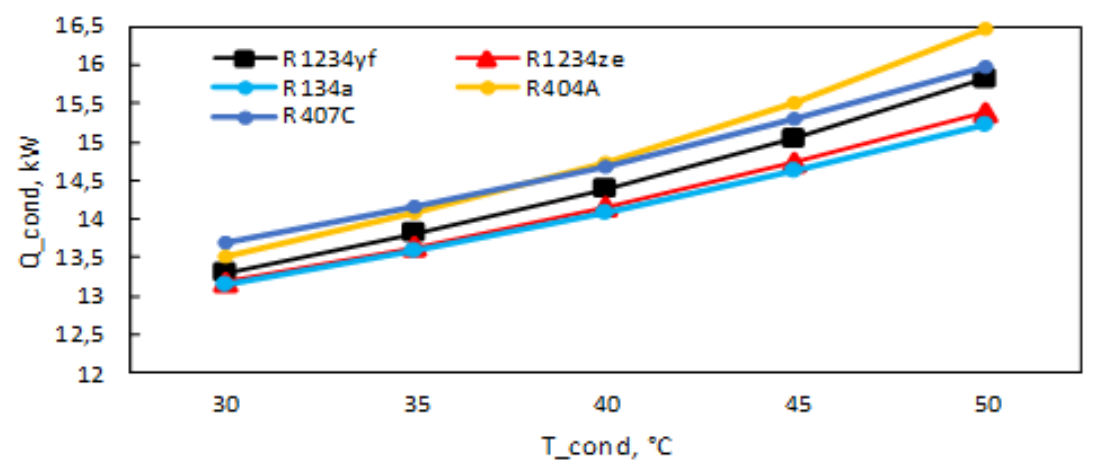

Fig. 10. Variation of condenser power as a function of condensing temperature 


\section{Conclusions}

A comparative analysis of the performance of certain refrigerants to see the new generation performance at low GWP of HFO refrigerants (R1234yf and R1234ze) compared to other HFC fluids on the vapor compression refrigeration cycle was carried out, followed a parametric study to see the effect of a few parameters, notably the evaporation temperature and the condensation temperature. This led us to the following conclusions

i. New generation HFOs fluids (R1234yf and R1234ze) have better performance than R134a fluid compared to that of HFC refrigerants (R404A and R407C); and the HFO-1234ze fluid gives a good coefficient of performance (3.14) compared to that of the HFO-1234yf fluid which gives a coefficient of performance of 3.0.

ii. The coefficient of performance of the vapor compression refrigeration cycle increases with the increase in the evaporation temperature for each refrigerant used, either of the HFC or HFO type; or HFO (R1234yf and R1234ze) gives good performance coefficients like R134a compared to other HFC fluids (404A and R407C).

iii. The coefficient of performance of the vapor compression refrigeration cycle decreases with the increase in the condensation temperature of each fluid used, of the HFC or HFO type.

iv. The mass flow rate decreases with the increase in the evaporation temperature for each refrigerant used, of the HFC or HFO type. It should also be noted that the R1234ze fluid uses a mass flow rate lower than that of the R1234yf and R134a fluids.

The R1234ze gives a coefficient of performance that approximates to the R134a fluid or this fluid has a very high GWP. The mass flow of refrigerant required by R1234a is lower compared to R134a. Overall, R1234a may be a better substitute for R134a.

\section{References}

[1] The Cooling Imperative Forecasting the size and source of future cooling demand, A report by The Economist Intelligence Unit. (2019). https://www.eiu.com/n/

[2] Abas, Naeem, Ali Raza Kalair, Nasrullah Khan, Aun Haider, Zahid Saleem, and Muhammad Shoaib Saleem. "Natural and synthetic refrigerants, global warming: A review." Renewable and Sustainable Energy Reviews 90 (2018): 557569. https://doi.org/10.1016/i.rser.2018.03.099

[3] Kudoma, Bongayi, and Memory Tekere. "Exploration of the environmental and socioeconomic implications of HCFC-22 phase-out for Botswana." Advances in Climate Change Research 12, no. 1 (2021): $108-118$. https://doi.org/10.1016/i.accre.2020.12.002

[4] Sanguri, Kamal, Kunal Ganguly, and Aman Pandey. "Modelling the barriers to low global warming potential refrigerants adoption in developing countries: A case of Indian refrigeration industry." Journal of Cleaner Production 280 (2021): 124357. https://doi.org/10.1016/j.jclepro.2020.124357

[5] Aziz, Azridjal, Thalal Thalal, and Afdhal Kurniawan Mainil. "Effect of Cooling Load on the Performance of R22 Residential Split Air Conditioner when Retrofitted with Hydrocarbon Refrigerant (HCR22)." Journal of Advanced Research in Fluid Mechanics and Thermal Sciences 48, no. 1 (2018): 100-108.

[6] Sidik, NA Che, and O. Adnan Alawi. "Computational investigations on heat transfer enhancement using nanorefrigerants." Journal of Advanced Research Design 1, no. 1 (2014): 35-41.

[7] Ciconkov, Risto. "Refrigerants: There is still no vision for sustainable solutions." International Journal of Refrigeration 86 (2018): 441-448. https://doi.org/10.1016/j.ijrefrig.2017.12.006

[8] Roy, Zunipa, and Gopinath Halder. "Replacement of halogenated refrigerants towards sustainable cooling systemA review." Chemical Engineering Journal Advances (2020): 100027. https://doi.org/10.1016/i.ceja.2020.100027

[9] Heredia-Aricapa, Y., J. M. Belman-Flores, Adrián Mota-Babiloni, Juan Serrano-Arellano, and Juan J. García-Pabón. "Overview of low GWP mixtures for the replacement of HFC refrigerants: R134a, R404A and R410A." International Journal of Refrigeration 111 (2020): 113-123. https://doi.org/10.1016/j.ijrefrig.2019.11.012 
[10] Gil, Bartosz, and Jacek Kasperski. "Efficiency evaluation of the ejector cooling cycle using a new generation of HFO/HCFO refrigerant as a R134a replacement." Energies 11, no. 8 (2018): 2136. https://doi.org/10.3390/en11082136

[11] Aprea, C., A. Greco, A. Maiorino, and C. Masselli. "The drop-in of HFC134a with HFO1234ze in a household refrigerator." International Journal of Thermal Sciences $127 \quad$ (2018): $117-125$. https://doi.org/10.1016/i.ijthermalsci.2018.01.026

[12] Belman-Flores, J. M., Adrián Mota-Babiloni, Sergio Ledesma, and Pavel Makhnatch. "Using ANNs to approach to the energy performance for a small refrigeration system working with R134a and two alternative lower GWP mixtures." Applied Thermal Engineering 127 (2017): 996-1004. https://doi.org/10.1016/i.applthermaleng.2017.08.108

[13] Daviran, Samaneh, Alibakhsh Kasaeian, Soudabeh Golzari, Omid Mahian, Shahin Nasirivatan, and Somchai Wongwises. "A comparative study on the performance of HFO-1234yf and HFC-134a as an alternative in automotive air conditioning systems." Applied Thermal Engineering 110 (2017): 1091-1100. https://doi.org/10.1016/i.applthermaleng.2016.09.034

[14] Longo, Giovanni A., Claudio Zilio, and Giulia Righetti. "Condensation of the low GWP refrigerant HFC152a inside a Brazed Plate Heat Exchanger." Experimental Thermal and Fluid Science 68 (2015): $509-515$. https://doi.org/10.1016/j.expthermflusci.2015.06.010

[15] Antunes, Arthur Heleno Pontes, and Enio Pedone Bandarra Filho. "Experimental investigation on the performance and global environmental impact of a refrigeration system retrofitted with alternative refrigerants." International Journal of refrigeration 70 (2016): 119-127. https://doi.org/10.1016/j.ijrefrig.2016.06.027

[16] Mota-Babiloni, Adrián, Joaquín Navarro-Esbrí, Pavel Makhnatch, and Francisco Molés. "Refrigerant R32 as lower GWP working fluid in residential air conditioning systems in Europe and the USA." Renewable and Sustainable Energy Reviews 80 (2017): 1031-1042. https://doi.org/10.1016/i.rser.2017.05.216

[17] Fang, Yu, Sergio Croquer, Sébastien Poncet, Zine Aidoun, and Yann Bartosiewicz. "Drop-in replacement in a R134 ejector refrigeration cycle by HFO refrigerants." international journal of refrigeration 77 (2017): 87-98. https://doi.org/10.1016/i.ijrefrig.2017.02.028

[18] Belman-Flores, J. M., V. H. Rangel-Hernández, S. Usón, and C. Rubio-Maya. "Energy and exergy analysis of R1234yf as drop-in replacement for R134a in a domestic refrigeration system." Energy 132 (2017): 116-125. https://doi.org/10.1016/i.energy.2017.05.074

[19] Yataganbaba, Alptug, Ali Kilicarslan, and İran Kurtbaş. "Exergy analysis of R1234yf and R1234ze as R134a replacements in a two evaporator vapour compression refrigeration system." International journal of refrigeration 60 (2015): 26-37. https://doi.org/10.1016/j.ijrefrig.2015.08.010

[20] Mendoza-Miranda, Juan Manuel, C. Salazar-Hernández, R. Carrera-Cerritos, J. J. Ramírez-Minguela, M. SalazarHernández, Joaquín Navarro-Esbrí, and Adrián Mota-Babiloni. "Variable speed liquid chiller drop-in modeling for predicting energy performance of R1234yf as low-GWP refrigerant." International Journal of Refrigeration 93 (2018): 144-158. https://doi.org/10.1016/j.ijrefrig.2018.06.016

[21] Mota-Babiloni, Adrián, Carlos Mateu-Royo, Joaquín Navarro-Esbrí, Francisco Molés, Marta Amat-Albuixech, and Ángel Barragán-Cervera. "Optimisation of high-temperature heat pump cascades with internal heat exchangers using refrigerants with low global warming potential." Energy 165 (2018): 1248-1258. https://doi.org/10.1016/j.energy.2018.09.188

[22] d'Angelo, José Vicente Hallak, Vikrant Aute, and Reinhard Radermacher. "Performance evaluation of a vapor injection refrigeration system using mixture refrigerant R290/R600a." International journal of refrigeration 65 (2016): 194-208. https://doi.org/10.1016/j.ijrefrig.2016.01.019

[23] Makhnatch, Pavel, Adrián Mota-Babiloni, Alejandro López-Belchí, and Rahmatollah Khodabandeh. "R450A and R513A as lower GWP mixtures for high ambient temperature countries: Experimental comparison with R134a." Energy 166 (2019): 223-235. https://doi.org/10.1016/i.energy.2018.09.001

[24] Rashed, M., O. Huzayyin, M. A. Kassem, and S. Kaseb. "A novel thermodynamic design model of a new HFO refrigerant single phase vapor jet cooling system." International Journal of Refrigeration 110 (2020): $153-167$. https://doi.org/10.1016/i.ijrefrig.2019.10.029

[25] Mateu-Royo, Carlos, Joaquín Navarro-Esbrí, Adrián Mota-Babiloni, Marta Amat-Albuixech, and Francisco Molés. "Thermodynamic analysis of low GWP alternatives to HFC-245fa in high-temperature heat pumps: HCFO-1224yd (Z), HCFO-1233zd (E) and HFO-1336mzz (Z)." Applied thermal engineering 152 (2019): $762-777$. https://doi.org/10.1016/j.applthermaleng.2019.02.047

[26] Touaibi, Rabah, Michel Feidt, Elena Eugenia Vasilescu, and Miloud Tahar Abbes. "Parametric study and exergy analysis of solar water-lithium bromide absorption cooling system." International Journal of Exergy 13, no. 3 (2013): 409-429. https://doi.org/10.1504/IJEX.2013.057358 
[27] Touaibi, Rabah, Hasan Köten, Michel Feidt, and Ozlem Boydak. "Investigation of three organic fluids effects on exergy analysis of a combined cycle: organic Rankine cycle/vapor compression refrigeration." Journal of Advanced Research in Fluid Mechanics and Thermal Sciences 52, no. 2 (2018): 232-245.

[28] Touaibi, Rabah, Michel Feidt, Elene Eugenia Vasilescu, and Miloud Tahar Abbes. "Modelling and Optimization Study of an Absorption Cooling Machine using Lagrange Method to Minimize the Thermal Energy Consumption." Journal of Advanced Research in Fluid Mechanics and Thermal Sciences 58, no. 2 (2019): 207-218.

[29] Klein, Sanford A., and F. L. Alvarado. "Engineering equation solver software (EES)." F-Chart Software: Madison, WI, USA (2013). 